\title{
Comprehensive Performance Evaluation of Business Incubator Based on AHP and Fuzzy Comprehensive Evaluation
}

\author{
Lu QIN ${ }^{\mathrm{a}}$, Zhuo-Xi YU ${ }^{\mathrm{b},{ }^{*}, \text { Jia-Qi HUANG }}{ }^{\mathrm{c}}$
}

School of Management Science and Information Engineering, Jilin University of Finance and

Economics, Jilin Province Key Laboratory of Internet Finance Changchun, China

a1484734011@qq.com, byzx8170561@163.com, '927237106@qq.com

${ }^{*}$ Corresponding author

Keywords: Business incubator, Evaluation system, Analytic Hierarchy Process(AHP), Fuzzy Comprehensive Evaluation Method.

\begin{abstract}
Business incubator has become a tool for governments to promote the development of small and medium-sized scientific and technological enterprises. Therefore, this paper constructs the evaluation index system of business incubator from four aspects: entrepreneurial environment, integrated hatching ability, social contribution and achievement benefit. Using Analytic Hierarchy Process(AHP) method to determine the weight of each index, using Fuzzy Comprehensive Evaluation Method to evaluate comprehensive performance. The empirical results provide the reference for the small and medium-sized enterprises to choose the incubation base reasonably. At the same time, it is shown that the combination of Analytic Hierarchy Process(AHP) and Fuzzy Comprehensive Evaluation Method is objective and effective for the comprehensive evaluation of incubator performance.
\end{abstract}

\section{Introduction}

In 1959, the first incubator, "the Scandinavian industrial center", was born in the United States. China's first incubator "Wuhan East Lake New Technology Venture Service Center” was established in 1987.Business incubator provides a series of service support for the newly established science and small and medium-sized technology enterprises, so it can reduce the entrepreneur's entrepreneurial risk and costs, improve the success rate of entrepreneurship and promote the transformation of scientific and technological achievements, to foster successful business and entrepreneurs[1].The performance evaluation of science and technology enterprise incubator project plays an important role in promoting the healthy development of science and technology enterprises, which can effectively improve the quality of science and technology enterprises in our country and overcome the blind pursuit of quantity of technology enterprises fundamentally [2].

This paper uses the method of AHP and Fuzzy Comprehensive Evaluation to evaluate the performance of business incubators. The weight of each index is determined by Analytic Hierarchy Process, and then the comprehensive evaluation of 163 business incubators in Changchun is carried out by using the Fuzzy Comprehensive Evaluation Method.

\section{Analytic Hierarchy Process (AHP) and Fuzzy Comprehensive Evaluation Method}

\section{Analytic Hierarchy Process}

Analytic Hierarchy Process is the decision-making method of qualitative and quantitative analysis on the basis of the elements that are always related to decision-making, which are decomposed into target layer, criterion layer and program layer.

Steps of Analytic Hierarchy Process (AHP):

(1) Identify target layer , criterion layer and program layer related to decision making;

(2) Construct discriminant matrix. From the second layer of the hierarchy model, for the same layer of each factor that belongs to (or affect) the upper layer, the contrast matrix is constructed by the pairwise comparison method and the 1-9 comparison scale until the lowest level. 
If the ratio of the importance of element $i$ to element $j$ is $a_{i j}$, the ratio of the importance of element $j$ to element $i$ is $a_{j i}=1 / a_{i j}$.

(3)Compute weight vector.

(4)Consistency test.

a)Calculate consistency index C.I. C.I. $=\frac{\lambda_{\max }-n}{n-1}$

$\lambda_{\max }$ represents the maximum eigenvalue, and $n$ represents the order of the discriminant matrix.

b)Calculate consistency ratio: C.R. $=\frac{\text { C.I. }}{R . I \text {. }}$

When C.I. $=0$, it is considered that the discriminant matrix is completely consistent;

When C.I. $<0.1$, it is accepted that the consistency of the discriminant matrix is acceptable;

When C.I. $>0.1$, it is considered that the discriminant matrix does not conform to the consistency requirement, and the discriminant matrix needs to be reconstructed and amended.

\section{Fuzzy Comprehensive Evaluation Method}

Fuzzy Comprehensive Evaluation Method is a comprehensive evaluation method based on fuzzy mathematics.The comprehensive evaluation method is based on the membership degree theory of fuzzy mathematics to transform the qualitative evaluation into quantitative evaluation, that is, using fuzzy mathematics to make a general evaluation of things or objects subject to various factors.

The steps of Fuzzy Comprehensive Evaluation Method :

(1) According to the establishment of a good index system to establish the object set, factor set (sub-factor set), alternative set (evaluation set, comment set);

(2)Use the appropriate method to establish the weight vector;

(3)Construct fuzzy matrices: establishing appropriate membership functions toconstruct good evaluation matrices;

(4)The synthesis of the evaluation matrix and the weight, the synthesis factor is used to synthesize it, and the result vector is explained

\section{Index System Construction}

The performance evaluation of the technology business incubator is mainly from two aspects: the enterprise's own management, operation and development status, as well as the survival and development of the incubation of enterprises and the growth of the situation [3].This paper refers to a large number of domestic and foreign literatures, combined with the data provided by the business incubator, taking into account the factors that affect the performance of the incubator project, from the qualitative and quantitative aspects of construction as shown in Table1 of the performance of science and technology incubator evaluation index system. 
Table 1Performance Evaluation Index System Enterprise Incubator

\begin{tabular}{|c|c|c|c|}
\hline & Primary index & Secondary index & $\begin{array}{l}\text { Index } \\
\text { property }\end{array}$ \\
\hline & & Geographical position $\left(C_{1}\right)$ & Qualitative \\
\hline & & $\begin{array}{l}\text { Average rent per } 3 \mathrm{~km} \text { around incubation } \\
\text { base }\left(C_{2}\right)\end{array}$ & Quantitative \\
\hline & Entrepreneurial & Government special support $\left(C_{3}\right)$ & Quantitative \\
\hline & $\left(B_{1}\right)$ & $\begin{array}{l}\text { The relationship between investors and } \\
\text { operating Institutions }\left(C_{4}\right)\end{array}$ & Qualitative \\
\hline & & Major ancillary facilities $\left(C_{5}\right)$ & Qualitative \\
\hline & & Main service function content $\left(C_{6}\right)$ & Qualitative \\
\hline & & Unit hatch area investment amount $\left(C_{7}\right)$ & Quantitative \\
\hline n & Integrated & $\begin{array}{l}\text { Unit hatch scale base management } \\
\text { personnel }\left(C_{8}\right)\end{array}$ & Quantitative \\
\hline $\begin{array}{l}\text { performance } \\
\text { of enterprise }\end{array}$ & $\begin{array}{l}\text { hatching } \\
\text { ability }\left(B_{2}\right)\end{array}$ & $\begin{array}{l}\text { Unit hatch scale hiring entrepreneurial } \\
\text { tutor }\left(C_{9}\right)\end{array}$ & Quantitative \\
\hline incubator & & Social service organization $\left(C_{10}\right)$ & Quantitative \\
\hline & & Hatching efficiency $\left(C_{11}\right)$ & Quantitative \\
\hline & Social & In the incubation business tax paid $\left(C_{12}\right)$ & Quantitative \\
\hline & contribution $\left(B_{3}\right)$ & Incubate the base of employment $\left(C_{13}\right)$ & Quantitative \\
\hline & & Graduation rate of enterprises this year $\left(C_{14}\right)$ & Quantitative \\
\hline & & $\begin{array}{l}\text { Unit hatch scale operation average } \\
\operatorname{profit}\left(C_{15}\right)\end{array}$ & Quantitative \\
\hline & $\begin{array}{l}\text { Achievement } \\
\text { benefit }\left(B_{1}\right)\end{array}$ & $\begin{array}{l}\text { The average total operating income in the } \\
\text { incubation business }\left(C_{16}\right)\end{array}$ & Quantitative \\
\hline & & $\begin{array}{l}\text { Accumulative total graduation } \\
\text { enterprise }\left(C_{17}\right)\end{array}$ & Quantitative \\
\hline & & $\begin{array}{l}\text { Unit hatch scale hatching enterprise } \\
\text { number }\left(C_{18}\right)\end{array}$ & Quantitative \\
\hline
\end{tabular}

\section{Empirical Research}

The data of this paper comes from an business incubator project in Changchun, China. which provides a comprehensive ranking of 163 business incubators according to the indexes provided.

\section{Determination of Weights by Analytic Hierarchy Process}

\section{Determine Target Layer, Criterion Layer and Program Layer}

According to the above established index system,we can divide it into target layer, criterion layer and program layer.

Target layer: $A$

Criterion layer: $B_{1}, B_{2}, B_{3}, B_{4}$.

Program layer: $C_{1}, C_{2}$, $\mathrm{L}, C_{18}$.

\section{Construct Discriminant Matrix}

The 15 experts related to the performance evaluation of the business incubator were selected to score 
each judgment matrix according to the above-mentioned index system.The following five matrices are the discriminant matrices constructed in this paper.

(1) $A$ : The discriminant matrix between the target layer and the criterion layer

(2) $B_{1}$ : The discriminant matrix between the first index in the criterion layer and its corresponding two-level index

(3) $B_{2}$ : The discriminant matrix between the second index in the criterion layer and its corresponding two-level index

(4) $B_{3}$ : The discriminant matrix between the third index in the criterion layer and its corresponding two-level index

(5) $B_{4}$ : The discriminant matrix between the fourth index in the criterion layer and its corresponding two-level index

\section{Calculate Weight Vector}

In this paper, we use the eigenvalue to obtain the weight vector. That is, the maximum eigenvalue and the corresponding eigenvectors of the discriminant matrix are obtained, and the normalized eigenvector of the largest feature root is used as the weight vector [4]. The results are $\left\{B_{1}, B_{2} B_{3}, B_{4}\right\}=\{0.1903,0.5553,0.0819,0.1725\}$

$\left\{C_{1}, C_{2}, C_{3}, C_{4}, C_{5}, C_{6}\right\}=\{0.0841,0.0084,0.0488,0.0201,0.0087,0.0201\}$

$\left\{C_{7}, C_{8}, C_{9}, C_{10}, C_{11}\right\}=\{0.2230,0.1236,0.1282,0.0246,0.0559\}$

$\left\{C_{12}, C_{13}\right\}=\{0.0410,0.0410\}$

$\left\{C_{14}, C_{15}, C_{16}, C_{17}, C_{18}\right\}=\{0.0237,0.0126,0.0212,0.0587,0.0563\}$

It can be seen from the above that the proportion of integrated hatching ability in the first-level index is 0.5553 , which is more than half the proportion. It shows that the integrated incubation ability is the most important index of the comprehensive evaluation of the performance of the business incubator and the success of the incubator.In the index layer of integrated hatching ability, the order of importance of the five two-level indexes is the unit hatching area investment amount, the unit hatching scale base management personnel, the unit hatching scale hiring entrepreneurial tutor, hatching efficiency, social service organization. Among them, the proportion of unit hatch area investment amount is the largest, followed by the unit hatch scale base management personnel and unit hatch scale hiring entrepreneurial tutor, which shows that capital and talent investment are important factors in its development for business incubators. The second and third in the ranking of one-level index are entrepreneurial environment and effective results, respectively 0.1903 and 0.1725 , indicating that these two indicators have almost equivalent status for the performance of business incubator ,in these two one-level index corresponding to the two-level indexes, the largest proportion of the geographical position indicators, followed by the accumulative total graduate enterprises, which shows that for high-tech and high talent technology business incubator evaluation, in addition to funds and talent are important factors in measuring its development, its own geographical location and the number of its cumulative number of graduates of these two indicators are also important factors that can not be ignored in measuring its development .

\section{Consistency Test}

The results of the consistency check of the five discriminant matrices obtained by the above-mentioned construction are 0.0641, 0.0340, 0.0985, 0.000, 0.0251, which are less than 0.1 ,passed the consistency test results.

\section{Application of Fuzzy Comprehensive Evaluation Method}

\section{Determine Object Sets, Factor Sets, and Alternative Sets}

The object set in this paper is: operation performance of science and technology enterprise incubator (A);factor set: primary index; sub- factor sets: secondary index ;Because it is ranked for 163 
business incubators, an optional set: $V=\{1,2, \mathrm{~L} 163\}$,which represents 163 business incubators.

\section{Construct Fuzzy Matrix}

Because the model includes both the factor set and the set of sub-factors, it is a two-level comprehensive fuzzy judgment. First, the one-level fuzzy comprehensive evaluation is carried out, and the results of the one-level fuzzy comprehensive evaluation are synthetically evaluated as a single factor evaluation matrix in the two-level fuzzy comprehensive evaluation.

The fuzzy matrices are constructed from the set of sub-factors, that is, the fuzzy matrices are constructed by the degree of subordination of the sub-factors to the alternative set, each of these factors is divided into quantitative and qualitative, and which should be dealt with separately. For the quantitative sub-factors, the membership function should be established according to the specific conditions, and then the membership degree is obtained and the fuzzy matrix is obtained; For qualitative indicators, its quantitative treatment [5].The method of this paper is to divide and assign these qualitative indexes according to the high and low grade, assuming that the evaluation expert serial number is $K, K=1,2, \mathrm{~L} N$.Each expert is asked to rate each index of each base, and then calculate the total score of each base divided by the expert number, and finally, which is normalized, so as to obtain membership degree of the two level index, and then get the fuzzy matrix corresponding to the sub-factor set.

The corresponding weights of the sub-factor sets are:

$$
\begin{aligned}
& \begin{aligned}
w_{1} & =\left(a_{11}, a_{12}, a_{13}, a_{14}, a_{15}, a_{16}\right) \\
& =(0.4421,0.0443,0.2565,0.1055,0.0460,0.1056) ;
\end{aligned} \\
& w_{2}=\left(a_{21}, a_{22}, a_{23}, a_{24}, a_{25}\right)=(0.4015,0.2227,0.2308,0.0443,0.1007) ; \\
& w_{3}=\left(a_{31}, a_{32}\right)=(0.5,0.5) ; \\
& w_{4}=\left(a_{41}, a_{42}, a_{43}, a_{44}, a_{45}\right)=(0.1373,0.3404,0.3261,0.1230,0.0732) ;
\end{aligned}
$$

$w_{1}, w_{2}, w_{3}, w_{4}$ are normalized weights.

The weighted average operator $M(\mathrm{Q} \oplus)$ is used to perform the fuzzy operation on $r_{1}, r_{2}, r_{3}, r_{4}$, and the fuzzy matrices of the factor set are : $R_{1}=w_{1} \mathrm{O} r_{1} ; \quad R_{2}=w_{2} \mathrm{O} r_{2}$;

$$
R_{3}=w_{3} \mathrm{Or}_{3} ; \quad R_{4}=w_{4} \mathrm{Or}_{4} ; \quad \text { So } R=\left[R_{1}, R_{2}, R_{3}, R_{4}\right]^{\prime} \text {. }
$$

From the above, we know that the weight of the factor set is:

$$
W=\left(W_{1}, W_{2}, W_{3}, W_{4}\right)=(0.1903,0.5553,0.0819,0.1725)
$$

Thus the final comprehensive evaluation is as follows: $B_{U}=W \mathrm{oR}$,

$B_{U}$ is $1 \times 163$ matrix, which is the result of ranking 163 bases.

This process is implemented by Matlab programming. The results set in the program are sorted from small to large.That is,the greater the results, the more backward sort, the better the evaluation, ranking the more forward.

The sorting result is: $\{42,117,48,70,45,27,1,35, \mathrm{~L} 158,159,160,161,162,163\}$

The above figures represent the business incubator. From the above results, it can be seen that the ranking is followed by business incubator 163,business incubator 162, business incubator161, business incubator 160 L business incubator 48, business incubator 117, and business incubator 42.For small and medium-sized enterprises to choose the incubator, business incubator 163 should be given priority, followed by business incubator 162 . 


\section{Conclusion}

Based on the combination of quantitative and qualitative analysis, this paper constructs an business incubator evaluation system composed of four first-level indicators and 18 second-level indicators for an enterprise incubator in Changchun City, the one-level indexes and the two-level indexes were analyzed, and the performance ranking of 163 business incubator was carried out by the method of AHP and Fuzzy Comprehensive Evaluation, which provides a reliable reference for the small and medium enterprises to choose the incubator base and the future development of the technology business incubator.

\section{Acknowledgment}

Science and Technology Research Project of the Education of Jilin Provinceunder grant No. 2016103.

\section{Reference}

[1] Lingjuan $\mathrm{Xu}$, Ninghui Liu. Study on influencing factors of performance of science and technology business incubator based on principal component analysis [J]. Science and Technology Progress and Countermeasures, 2008,(11): 213-215.(In Chinese)

[2] Lu Zhang, Cheng Peng. Study on performance evaluation of science and technology enterprise incubator project based on AHP-FCEM [J]. Project Management Technology, 2015, (7): 84-88. (In Chinese)

[3] Xiliang Wang. Technology business incubator performance evaluation [D]. Tianjin University, 2012. (In Chinese)

[4] Zhijian Zeng, Qianqian Zhang, Zuo Nan. Study on Evaluation System of Science and Technology Business Incubator Based on Fuzzy Analytic Hierarchy Process [J] .Journal of Finance and Economics, 2014, (6): 119-122. (In Chinese)

[5] Peng Zhang ,Haojian Zhan. Performance Evaluation of DEA Technology Incubator - Taking Guangdong as an Example [J]. Science and Technology Management Research, 2010, (14): 78-81. (In Chinese) 